\title{
Capital Social y Participación, una perspectiva desde el Cono Sur de América: Porto Alegre, Montevideo y Santiago de Chile
}

\begin{tabular}{c}
\hline \hline Patricio Valdivieso \\
Universidad Bernardo O'Higgins \\
Chile \\
\hline \hline
\end{tabular}

\begin{abstract}
Resumen: En este estudio presento evidencias sobre la participación ciudadana y el Capital Social (CS) en tres casos sudamericanos - Porto Alegre, Montevideo y Santiago de Chile-, con el propósito de revitalizar el debate sobre la opinión pública, cultura política y CS. El estudio parte de los siguientes supuestos: el CS es el resultado de decisiones racionales de las personas, y los diseños políticos, las instituciones y la cultura política tienen efectos en esas decisiones. Con ayuda de un modelo de utilidad, datos de encuestas e información complementaria, analizo información sobre asociativismo y confianza, y otras variables socio-económicas, demográficas y políticas relacionadas. Las conclusiones son: a mediados de la década del 2000, Montevideo, Porto Alegre y Santiago de Chile disponían de un stock de CS equivalente al de sociedades desarrolladas; en esas ciudades, y por extensión en los países, los factores político-institucionales y de cultura política tuvieron efectos en la confianza y la disposición de las personas a participar, operando de forma variada, en relación con distintos contextos y situaciones de participación. En el análisis más desagregado del caso de Chile en el nivel municipal, se observan las mismas relaciones.
\end{abstract}

Palabras-clave: capital social; participación; confianza; Brasil; Chile; Uruguay

Abstract: This study presents evidence on citizen participation and social capital (SC) in three South American cases - Porto Alegre, Montevideo and Santiago of Chile, in order to revitalize the debate on public opinion, political culture and SC. The study has the following assumptions: the SC is the output of rational decisions of individuals and political designs and institutions and political culture have an impact on those decisions. Using a utility model, survey data and information, I analyze information on associative life and trust, and other socio-economic, demographic and political information. The conclusions: in the mid.2000s, Montevideo, Porto Alegre and Santiago de Chile had a stock of SC equivalent to that of developed societies; in those cities, and by extension, countries, political and institutional factors and political culture had an effect on trust and the willingness of people to take part in associative life, in relation to different contexts and situations of participation. In the more disaggregated analysis of the case of Chile on local level, the same relationships are observed.

Keywords: social capital; participation; trust; Brazil; Chile; Uruguay

OPINIÃO PÚBLICA, Campinas, vol. 18, n 1, Junho, 2012, p.129- 153 
OPINIÃO PÚBLICA, Campinas, vol. 18, n 1, Junho, 2012, p. $129-153$

\section{Introducción}

En la literatura del desarrollo se ha subrayado la importancia de las estructuras sociales y de la cultura cívica, en cuanto condiciones que pueden promover la cohesión, la integración y el desarrollo sustentable (BAQUERO, 2003). Ellas han sido conceptualizadas como "Capital Social" (CS), y en la actualidad ese término tiene un espacio en la investigación y sirve de supuesto en numerosas políticas públicas que promueven la vida asociativa, la confianza y la participación de los ciudadanos como agentes y socios estratégicos en la agenda pública (INTERAMERICAN DEVELOPMENT BANK, 2005).

No obstante la riqueza de significados atribuidos al concepto de CS, no hay muchos estudios empíricos que precisen realmente de qué se está hablando, y los más destacados se refieren a grupos de países o a casos locales muy particulares (NORRIS, 2002; WELZEL, INGLEHART, DEUTSCH, 2005, CASTILLO, 2006). Excepcionales son los trabajos de Baquero y el equipo de investigación del CS en el Cono Sur de América Latina (BAQUERO, 2007) y Freitag en Europa Central (FREITAG, 2006). En sintonía con los estudios indicados, en este estudio sintetizo conocimientos generados por la investigación empírica y comparada sobre el CS en Porto Alegre, Montevideo y en Santiago de Chile, en el marco de la ejecución del proyecto de Investigación "Factores Políticos e Institucionales en la formación del Capital Social" (FONDECYT NR. 1110413).

En este artículo presento evidencias empíricas del CS y de los factores que podrían explicar la formación del mismo. Siguiendo la hoja de ruta iniciada por la investigación de Baquero (BAQUERO, 2007), lo hago a partir del análisis comparado de información recabada en tres ciudades sudamericanas (Montevideo, Porto Alegre, Santiago de Chile). El estudio considera los conceptos y las variables destacadas por la literatura sobre CS, y sigue el derrotero de la investigación teórica y empírica, con el objeto de sumar las observaciones y hallazgos sobre los tres casos investigados y comparados al conocimiento de otras investigaciones realizadas hasta la fecha (en particular PUTNAM, 1995; NORRIS, 2002; WELZEL, INGLEHART, DEUTSCH, 2005; GIESSEL, 2006; FREITAG, 2006; BAQUERO, 2007). La metodología consistió en revisar literatura sobre el CS y cultura política, precisar un modelo decisional que ayude a explicar la formación del CS, operacionalizar conceptualizaciones en variables de observación, construir y aplicar encuestas a muestras representativas de población en tres ciudades del Cono Sur de América Latina, construir índices de CS y de variables relacionadas, observar tendencias y relaciones, con ayuda de métodos de regresión. El artículo comienza con la explicitación del modelo de utilidad que explica las decisiones de participar y tener confianza, sigue con la aclaración de los conceptos de observación, después presenta tendencias observadas en Montevideo, Porto Alegre y Santiago, en relación con los mismos, subrayando el efecto de las variables de naturaleza política, institucional y de cultura política en los procesos de formación del CS, y finalmente agrega un microanálisis del efecto de las comunas chilenas y sus condiciones políticas e institucionales en el CS. Al terminar, hay una recapitulación de observaciones y hallazgos de interés para continuar desarrollando esta línea de investigación. 


\section{Decisiones y formación del Capital Social}

En la literatura clásica, el Capital Social (CS) es el resultado de decisiones que toman las personas y las comunidades. A partir del supuesto que el CS "hace posible alcanzar metas que no se obtendrían con su ausencia o sólo a un alto costo" (COLEMAN, 1990, p.305), se puede partir del supuesto que el CS es el resultado de decisiones que toman las personas en relación con sus metas, bajo ciertas condiciones dadas por su función de utilidad.

Todas las personas tienen una predisposición natural a confiar en los demás y a la vida social, pero también restricciones de tiempo, de recursos, y numerosas posibilidades para tomar decisiones. Por lo tanto, las decisiones que conducen a la formación del CS tienen costos de oportunidad. En principio, cada persona estará dispuesta a confiar y a participar en una oferta de vida asociativa, si esa oferta coincide con su punto preferido. Aunque no coincida exactamente, si hay buenas razones, incentivos, podría flexibilizar su posición, aceptando ofertas de vida asociativa que coincidan con los puntos de su curva de indiferencia. Esto ocurre, porque las personas están capacitadas para discernir, evaluar y tomar decisiones, en relación con otras personas, con la sociedad y con situaciones cambiantes, y en esos procesos influyen diversos factores. En este sentido, siguiendo la lógica de la Figura 1, es posible suponer el efecto de un conjunto de factores que influyan en las preferencias y en la disposición a tener confianza y aceptar propuestas de vida asociativa que se alejen un poco de la localización preferida inicial, pero que se sitúen dentro de los límites de la curva de indiferencia.

\section{Figura 1}

\section{Un modelo de formación de Capital Social}

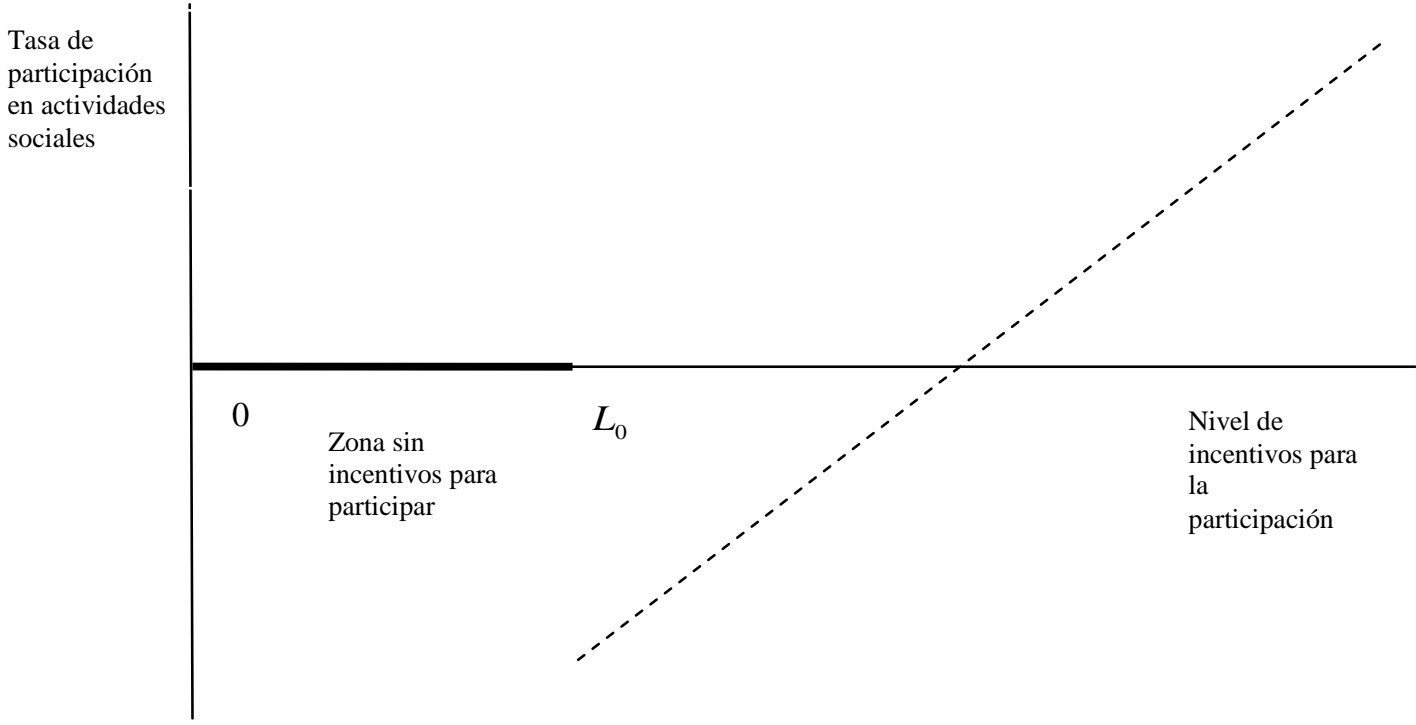


La Figura 1 muestra que las personas pueden responder positivamente a factores que incentivan la participación y la confianza. Propone que debe existir un nivel mínimo $L_{0}$ que marca el límite, antes del cual no estarán dispuestas a participar, ni a sentir grados razonables de confianza. Superado ese límite, la confianza y la participación se incrementan. En la medida que los factores sean adecuados y valorados, las personas tendrán incentivos para participar más en instancias de vida asociativa, y manifestarán mayor grado de confianza. En suma, en la medida que haya factores que operen como incentivos, en sentido positivo, se incrementará la confianza y aumentará la probabilidad de decisiones de participación, y estarán operando dinámicas de formación de CS.

En la literatura del CS, las decisiones de participar y la confianza se explican porque las ofertas de vida asociativa contienen incentivos de distinto tipo, tales como son los recursos físicos y simbólicos, interacciones interpersonales que transmiten conocimientos, recursos que se ponen en movimiento y que favorecen el logro de metas individuales y colectivas (BOURDIEU, 1980; COLEMAN, 1990). Asimismo, desde la perspectiva de los desincentivos, la oferta de vida asociativa significa tener que asumir numerosos costos (OSTROM, 1990). En suma, las personas, siguiendo su tendencia natural a la confianza y la vida gregaria, se afilian o participan en asociaciones y desarrollan relaciones de confianza debido a procesos de toma de decisión racional, donde influyen las interacciones entre sus características personales, sus condiciones de vida, sus preferencias y ciertos incentivos tangibles o intangibles por el lado de la oferta del asociativismo y de las condiciones relacionadas.

Por las razones expuestas, cabe considerar con seriedad el concepto de función de utilidad en la explicación del CS, en los siguientes términos: las personas toman la decisión de participar en la vida asociativa e incrementan su confianza, si se da la condición que la utilidad que reporta participar y sentir confianza es mayor que la utilidad que reporta el no participar y la desconfianza.

a)

$$
U(X, Y, P) \geq U(X, Y, N O P)
$$

Donde $\mathrm{X}$ e $\mathrm{Y}$ representan factores asociados a la confianza y la decisión P (participar) y a NP (no participar y desconfianza). La condición indica que la utilidad de participar en una asociación y tener confianza debe ser mayor a la utilidad que reporta no participar. Por extensión, el estudio del CS debe investigar factores asociados con incentivos y costos de oportunidad de la participación y la confianza.

En la práctica, en el día a día, las decisiones pueden ser consideradas como el resultado de complejos procesos de razonamiento, donde operan "variables latentes". Las decisiones reflejan procesos continuos, no observables, por medio de los cuales entran en consideración costos y beneficios. En este sentido, ante la posibilidad de participar y confiar, las personas razonarán comparando los costos y los beneficios, y tomarán la decisión de participar y confiar si llegan a la conclusión que el beneficio neto es positivo. En términos formales, podemos representar el beneficio neto con la siguiente expresión:

b)

$$
Y^{*}=\alpha+\beta x+€
$$


Donde $Y^{*}$ representa la variable "latente" no observada, $\alpha$ es la constante, $\beta$ el vector de parámetros a ser estimados, $X$ la información de los parámetros o variables explicativas, $Y €$ los shocks aleatorios de factores no controlables. De éste modo se puede asumir que el proceso de tomar decisiones sigue una rutina, por medio de la cual se compara grados de utilidad.

$$
\begin{array}{lll}
Y=1 & \text { si } & Y^{*} \geq 0 \\
Y=0 & \text { si } & Y^{*}<0
\end{array}
$$

Donde $Y^{*}$ debe ser entendida como la utilidad neta de participar en una instancia de vida asociativa y sentir confianza, en el razonamiento de quien debe tomar la decisión, e $Y$ representa el efecto observado de la decisión. Por lo tanto, la decisión de participar y confiar o no hacerlo estará condicionada por:

c) $\quad Y^{\prime}=U(X, Y, P)-U(X, Y, N P)$

Dado que no es posible observar las variables latentes de $Y^{*}$, el estudio del CS debe buscar referentes empíricos que representen la utilidad y los parámetros que influyen en los proceso de toma de decisión. En la investigación se puede usar información generada por encuestas de opinión aplicadas a muestras representativas de población. Con este tipo de insumos y ciertas normalizaciones es posible observar muestras con valores 1's y 0's que representen tener o no confianza y decisiones de participar o no participar en instancias de vida asociativa. Con información sobre las decisiones se puede estimar el impacto de factores en la probabilidad de obtener un 1. En términos formales, podemos sintetizar lo anterior con ayuda de la siguiente condición:

d) $\quad \operatorname{Pr}(Y=1)=\operatorname{Pr}\left(Y^{*} \geq 0\right)$

Tomando en consideración la ecuación a), con ayuda de un poco de algebra, la condición de $\operatorname{Pr}\left(Y^{*} \geq 0\right)$, ubicada a la izquierda de la ecuación, indica los parámetros que ayudan a predecir la probabilidad que una persona tenga una función de utilidad mayor o igual a $\mathrm{O}$, y en consecuencia confie y tome la decisión de participar.

Como se puede advertir, el razonamiento anterior justifica el uso de un modelo binario estándar (Probit). Uno de los supuestos a tener en consideración es que la capacidad de explicar del modelo descansa en la información que aportan las variables observables, aquellas que se pueden medir y constatar. Por lo tanto, se asume que de existir variables no observables que participan en el proceso de decisión, éstas tienen un efecto marginal.

En suma, para poder estimar el impacto de los factores que conducen a $\operatorname{Pr}\left(Y^{*}>0\right)$, se requiere información sobre decisiones de participación en instancias de vida asociativa y confianza, e información sobre factores e incentivos que influyen en la función de utilidad de cada persona. 


\section{Conceptualización y estimaciones}

En la literatura hay numerosas definiciones y operacionalizaciones del CS (cf. NORRIS, 2002; CASTILLO, 2005; FREITAG, 2006; BAQUERO, 2007). En este estudio trabajaré con la conceptualización más difundida desde los trabajos de Coleman y Putnam (COLEMAN, 1990; PUTNAM, 1993), a saber, el CS entendido como vida asociativa y los recursos relacionados con ella, tales como son las redes sociales, normas de reciprocidad y confianza. Aceptando el supuesto que la vida asociativa y la confianza son dimensiones centrales del CS, observaré diversos tipos de asociativismo y de confianza como indicadores del stock de CS en Montevideo, Porto Alegre y Santiago de Chile.

Siguiendo el razonamiento de Coleman, que el CS corresponde a redes comunitarias cuya función es crear valor (COLEMAN, 1990, p.311.312), partiré del supuesto que las relaciones interpersonales pueden adoptar diversos formatos, dependiendo de contextos y situaciones específicas. En otras palabras, la vida asociativa comprende todas aquellas formas de asociativismo que beneficien al conjunto de los ciudadanos y que no vayan en contra de una lógica o de prácticas democráticas. Con esa premisa, observaré el CS como participación en cuatro categorías de vida asociativa: asociaciones de voluntariado (AV), incluye participación en organizaciones de beneficencia, asociaciones comunitarias y/o medioambientales (COLEMAN, 1990, p.312; WELZEL et al, 2005, p.3; FREITAG, 2006, p.3); asociaciones religiosas (AR), forma de asociativismo extendida en Brasil, Chile y América Latina (datos que lo demuestran en más de veinte países latinoamericanos disponibles en www.LapopSurveys.org.); grupos de interés o asociaciones utilitarias (AU), incluye participación en asociaciones profesionales, clubes deportivos, grupos etarios, centro de padres, etc. (nomenclatura equivalente en WELZEL et al, 2005, p.9); acciones colectivas desafiantes (AC), tales como son las protestas, colectas de firmas o huelgas (tratadas en Norris, 2002 y Geissel, 2006). En la literatura se argumenta que las asociaciones de voluntariado subordinan beneficios inmediatos por objetivos de largo plazo (PUTNAM 1995, p.72; WELZEL et al, 2005, p.9), los grupos de interés o utilitarios, en cambio, tratan de alcanzar sus intereses específicos, con una racionalidad más estratégica e instrumental (COLEMAN, 1990, p.312), y las acciones colectivas representan un asociativismo no convencional ni estructurado que pone en movimiento redes y recursos individuales (COLEMAN, 1990, p.305; WELZEN et al, 2005, p. 8; GEISSEL, 2006, p.3).

Por otra parte, observaré también la participación política convencional (institucionalizada, electoral) y el interés en la política como manifestaciones de una cultura cívica democrática positiva para la formación del CS, lo que ha sido destacado y documentado latamente (CASTILLO, 2006). Ambas conductas generan conectividad interpersonal, favorecen la tolerancia. Numerosos estudios argumentan sobre la importancia de la participación y el interés por la política para la estabilidad democrática, con evidencias en casos; así, en la literatura de educación ciudadana esas conductas son considerada una virtud (DETJEN, 2000).

La confianza y el consentimiento son conceptos centrales, en cuanto representan actitudes facilitadoras de acciones colectivas en torno a metas comunes (LOCKE, 2002, p.481.483). Entre las modalidades posibles de confianza social, cabe destacar la confianza interpersonal o social, factor básico que posibilita cualquier tipo de relación humana (historicamente documentado por Tilly, Tilly, 1975; 
Rose, 1998) y en las instituciones comunes que favorecen el buen funcionamiento del sistema político y la gobernabilidad (PUTNAM, 1996; BAQUERO, 2003, p. 19.20)1.

En la literatura de enfoque más sociológico, las variables ya indicadas del CS son tratadas en relación con un conjunto de indicadores demográficos, socioecómicos y relativos a la calidad de vida de las personas y de sus asociaciones (WELZEL, INGLEHART, DEUTSCH, 2005; RUBENSON, 2005): el género, el nivel educacional y el nivel de ingreso; las condiciones de asociatividad (infraestructura de organizaciones), en los lugares donde las personas viven, pues resulta ser razonable pensar que si ellas disponen de instancias para la participación en sus barrios y conocimientos respecto a éstas, tendrán mejor predisposición para participar (consignado en estudios monográficos sobre asociativismo religioso en localidades; Mara, 2004). El bienestar personal, la calidad de vida y las expectativas futuras también ayudan a explicar.

En la literatura más institucionalista, se presta atención a los factores de naturaleza política, institucional y a la cultura política. El grado de satisfacción con la democracia manifiesta la percepción que tiene las personas sobre los logros de los gobiernos y de las instituciones, en sus respectivos países. Más específicamente aún, el grado de seguridad que tengan las personas también manifiesta su percepción del desempeño que tienen los gobiernos y las instituciones, en cuanto a su capacidad para proveer empleo y buenas condiciones socioeconómicas, y combatir el crimen y cautelar por el orden público (informaciones para América Latina disponibles en Hagopian, 2005). Por último, el CS es tratado también en relación con un conjunto de variables actitudinales de cultura política y competencias ciudadanas (WELZEL, INGLEHART, DEUTSCH, 2005; GEISSEL, 2006). Entre ellas destaca el sentido de solidaridad, que expresa competencias sociales habilitantes para las acciones colectivas. El principio de solidaridad, cuya manifestación es cierto grado de identificación social y de sentido del bien común, es un agente de la cohesión social y de la participación (MARA, 2004); en efecto, para que las personas se sientan motivadas por causas colectivas es necesario que exista algún grado de identificación entre esas causas y sus propios principios y motivaciones.

En este estudio partiré por observar el CS en Montevideo, Porto Alegre y Santiago de Chile con ayuda de la información recabada mediante la aplicación de una encuesta en las tres ciudades, el año 2005, por medio de índices sumativos que representan el stock de vida asociativa en cuatro categorías (voluntariado, grupos de interés, religiosas y acciones colectivas desafiantes), la confianza social y en las instituciones, y la participación y el interés por la política. Los índices de participación y confianza representan variables dicotómicas que ayudan a diferenciar entre personas que participan o no, personas que tienen confianza o no. Posteriormente, con información de las mismas encuestas, incorporaré en el análisis otros índices que sintetizarán informaciones demográficas, socioeconómicas y políticas, con el propósito de explorar relaciones que ayuden a explicar las decisiones de las personas que confían y deciden participar en instancias de vida asociativa. La atención estará centrada en entender el aporte de esas informaciones para explicar la probabilidad que las personas decidan participar y tener confianza o no, y muy en particular el efecto que puedan tener los factores de naturaleza política e institucional en

\footnotetext{
1 Más antecedentes y literatura sobre esta tipología disponibles en Valdivieso (2009).
} 
ello. Finalmente, en el caso de Santiago de Chile exploraré una estimación del efecto que tienen las comunas y sus características en las decisiones de participar y de tener confianza.

\section{Tendencias del Capital Social en Montevideo, Porto Alegre y Santiago de Chile}

En este apartado presento informaciones sobre tendencias de participación y confianza, en porcentajes, en Porto Alegre, Montevideo y Santiago de Chile el año 2005. La metodología consistió en operacionalizar conceptos en forma de preguntas de una encuesta, aplicarla en las tres ciudades, poblar bases de datos, y construir índices sumativos. El concepto "vida asociativa" fue operacionalizado y observado por medio de índices de participación en asociaciones de voluntariado (objetivos filantrópicos), en asociaciones utilitarias (objetivos instrumentales), en asociaciones religiosas (identificación con ciertos credos y formas de vida relacionadas) y en acciones colectivas desafiantes (identificación con actitudes críticas y el inconformismo) ${ }^{2}$. Esta tipología hizo posible la comparación con observaciones y hallazgos de estudios sobre otros lugares del mundo (tales como RUBENSON, 2005; WELZEL, INGLEHART, DEUTSCH, 2005; GEISSEL, 2006). El siguiente cuadro sintetiza las principales tendencias observadas con respecto a la participación y la confianza en los tres casos sudamericanos:

\section{Cuadro 1}

Participación y Confianza en Montevideo, Porto Alegre y Santiago (\%)

2005

\begin{tabular}{|l|l|l|l|}
\hline & Montevideo & Porto Alegre & Santiago \\
\hline Participación Voluntariado & 18,00 & 10,00 & 10,40 \\
\hline Participación en grupos de interés & 17,20 & 9,43 & 9,40 \\
\hline Participación en asociaciones religiosas & 12,00 & 16,86 & 26,20 \\
\hline Participación en acciones colectivas & 33,20 & 15,10 & 16,60 \\
\hline Confianza en otra gente & 70,80 & 46,27 & 51,40 \\
\hline Confianza en las instituciones & 19,80 & 28,82 & 29,00 \\
\hline Votar en elecciones & 88,20 & 87,30 & 72,00 \\
\hline Discutir sobre política & 66,80 & 65,69 & 37,20 \\
\hline Informarse & 71,80 & 67,60 & 55,80 \\
\hline
\end{tabular}

El cuadro contiene porcentajes de respuestas afirmativas a las preguntas incluidas en los índices de participación y confianza. Fuente: Bases de datos de encuestas aplicadas en Montevideo, Porto Alegre y Santiago de Chile. Disponibles en: $<$ http://www.capital-social.com/wp/?page_id=251>.

\footnotetext{
2 Definí los índices como variables dicotómicas, porque ellas permiten diferenciar entre quienes participan y quienes no, quienes tienen confianza y quiénes no. Dado que el cuestionario aplicado contiene distintas preguntas y posibilidades de respuesta sobre vida asociativa y confianza, que manifiestan diversos formatos del CS, consideré pertinente sintetizar la información en índices de participación y confianza. A partir de distintas preguntas y posibilidades de respuesta, procedí a homogenizar en una sola medida, con sólo dos posibilidades: participa o no, tiene confianza o no. El trabajo con variables dicotómicas conduce a considerar el punto medio de los valores posibles como el criterio que lleva a diferenciar (el punto medio de la variable es equidistante de los extremos, está a igual distancia, y esto representa un criterio objetivo); si la variable toma valores entre 0 (no participar) o 1 (participar), el 0,5 será el límite y el criterio para diferenciar entre quienes participan y quiénes no. Descarté la posibilidad de trabajar con variables que tengan mayor cantidad de grados, por ejemplo participa nada, algo, más o menos, mucho, porque aumentaría la subjetividad en el proceso de clasificación.
} 
En las tres ciudades, los porcentajes de participación en asociaciones son relativamente bajos, y ello es congruente con las observaciones de otros casos en el mundo (WELZEL, INGLEHART, DEUTSCH, 2005, p.33). En Montevideo se observa una mayor participación en acciones colectivas desafiantes y en grupos de interés ${ }^{3}$, y menor en asociaciones religiosas, lo que es consistente con numerosas observaciones cualitativas respecto al alto grado modernización, secularización y de educación cívica de la población uruguaya, y su alta propensión a participar (YAFFÉ, 2005; BUQUET, 2005). En comparación, Santiago de Chile muestra mayor participación en asociaciones religiosas que Porto Alegre, y mucho mayor que Montevideo ${ }^{4}$. Por otra parte, en concordancia con los hallazgos de otros estudios (KIM 2005), las informaciones del cuadro indican un alto grado de confianza social, y bajo grado de confianza en las instituciones. Montevideo destaca por tener los mayores porcentajes de confianza social y desconfianza en las instituciones, lo que puede tener relación con la coyuntura política en ese país, cuando se aplicó la encuesta (transición hacia un gobierno de izquierda). Sumariamente, desde la perspectiva de la participación en la vida asociativa y de la confianza, los tres casos tienen niveles de CS equivalentes a los observados en los casos de sociedades modernas y desarrolladas, en otros lugares del mundo (WELZEL et al, 2005)

En Santiago se observa un porcentaje de participación política más bajo que en Porto Alegre y en Montevideo, en los tres casos un considerable grado de discusión sobre política, no obstante ser bastante más bajo el grado de la acción de informarse. Cabe consignar que la alta participación política en los tres países refleja la obligatoriedad de votar para quienes están inscritos en los registros electorales.

En síntesis, las observaciones del cuadro reafirman que el CS puede ser observado por medio de indicadores de vida asociativa y de confianza. El stock de CS en forma de asociaciones y de confianza en las instituciones parece ser moderado en todas partes, mientras que la confianza social es mayor. Estas constataciones no constituyen una evaluación, en sentido optimista ni pesimista, en relación con el debate en torno al aumento o la erosión del CS (PUTNAM, 2000; NORRIS, 2002). Sin embargo, ellas sugieren que el año 2005 los niveles de CS de Montevideo, Porto Alegre y Santiago de Chile eran equivalentes a los que se observaban en las sociedades industriales y postindustriales, y que, desde esta perspectiva, los respectivos países tenían buenas condiciones para su desarrollo.

\section{El Capital Social, factores socioeconómicos y cultura política, y causalidades}

En este apartado centro mi atención en las relaciones que puedan existir entre las variables del CS, cuyas tendencias han sido observadas previamente, y entre ellas y otras variables demográficas, socioeconómicas, políticas y de cultura política consideradas por la literatura. La metodología consistió en operacionalizar conceptos en forma de preguntas que fueron introducidas en los cuestionarios aplicados en las tres ciudades. Con la información de la base de datos poblada, procedí a construir índices sumativos, normalizados en el intervalo 0 a 1 , de variables independientes que representan

\footnotetext{
${ }^{3}$ Las causas debiesen ser investigadas en relación con la pregunta por las razones que explican formas de participación más funcionales en unos casos y las relaciones de ello con grados de modernización.

4 En Uruguay, el grado de secularización es mayor que en Chile y que en Brasil, y esto podría explicar, en parte, las observaciones.
} 
factores que podrían influir en la probabilidad de participar y de confiar. Con las informaciones de cada caso (Montevideo, Porto Alegre y Santiago de Chile), mediante regresiones probit estándar obtuve cuatro modelos binarios, donde están presentes las cuatro formas de medir la participación en la vida asociativa (voluntariado, grupos de interés, religiosos y acciones colectivas; modelos 1,2,3, y 4 respectivamente). Aquí, la observación está centrada en captar e interpretar el efecto marginal que tienen las variables de naturaleza política, institucional o de cultura política sobre la probabilidad de participar o confiar.

\section{Cuadro 2}

\section{Factores causales de la participación, Montevideo}

2005

\begin{tabular}{|c|c|c|c|c|}
\hline $\begin{array}{l}\text { Variables } \\
\text { independientes }\end{array}$ & $\begin{array}{l}\text { Modelo 1: } \\
\text { IPAS }\end{array}$ & Modelo 2: IPAU & $\begin{array}{l}\text { Modelo 3: } \\
\text { IPAR }^{1}\end{array}$ & $\begin{array}{l}\text { Modelo 4: } \\
\text { IPACD }\end{array}$ \\
\hline $\begin{array}{l}\text { Participación } \\
\text { voluntariado (IPAS) }\end{array}$ & $\cdots$ & $\begin{array}{l}0,1839 * * * * \\
(0,0478)\end{array}$ & $\begin{array}{l}0,2154 * * * \\
(0,048)\end{array}$ & $\begin{array}{l}0,158^{*} \\
(0,086)\end{array}$ \\
\hline $\begin{array}{l}\text { Participación grupos } \\
\text { de interés (IPAU) }\end{array}$ & $\begin{array}{l}0,356^{* * * *} \\
(0,072)\end{array}$ & $\ldots$ & $.0,122^{*}(0,066)$ & $\begin{array}{l}0,567^{* * *} \\
(0,116)\end{array}$ \\
\hline $\begin{array}{l}\text { Participación acciones } \\
\text { colectivas (IPACD) }\end{array}$ & $0,076(0,052)$ & $\begin{array}{l}0,2301 * * * \\
(0,046)\end{array}$ & $.0,068(0,049)$ & $\cdots$ \\
\hline $\begin{array}{l}\text { Confianza en otra } \\
\text { gente (ICG) }\end{array}$ & n.s. & n.s. & n.s. & $\begin{array}{l}0,292^{* *} \\
(0,146)\end{array}$ \\
\hline $\begin{array}{l}\text { Confianza instituciones } \\
(\mathrm{ICI})\end{array}$ & n.s. & n.s. & $\begin{array}{l}0,255^{* * * *} \\
(0,078)\end{array}$ & n.s. \\
\hline Sexo (S) & n.s. & n.s. & $\begin{array}{l}-0,043^{* * *} \\
(0,027)\end{array}$ & n.s. \\
\hline Estudios (NE) & $\begin{array}{l}0,016 * * * \\
(0,004)\end{array}$ & n.s. & n.s. & $0,009(0,006)$ \\
\hline Edad & n.s. & $\begin{array}{l}0,0018^{* * * *} \\
(0,001)\end{array}$ & n.s. & n.s. \\
\hline Ingresos (NI) & n.s. & n.s. & n.s. & n.s. \\
\hline Calidad de vida (ICV) & n.s. & n.s. & n.s. & n.s. \\
\hline $\begin{array}{l}\text { Bienestar personal } \\
\text { (IBP) }\end{array}$ & n.s. & n.s. & n.s. & $\begin{array}{l}-0,117^{* *} \\
(0,060)\end{array}$ \\
\hline Inseguridad (IIN) & n.s. & n.s. & $\begin{array}{l}\cdot 0,177^{* *} \\
(0,088)\end{array}$ & n.s. \\
\hline Participar en política & n.s. & n.s. & n.s. & $\begin{array}{l}0,275^{* * * *} \\
(0,081)\end{array}$ \\
\hline $\begin{array}{l}\text { Satisfacción con la } \\
\text { democracia (ISD) }\end{array}$ & n.s. & $0,055(0,0432)$ & n.s. & $\begin{array}{l}-0,103 \\
(0,066)\end{array}$ \\
\hline $\begin{array}{l}\text { Solidaridad e } \\
\text { identificación (ISOI) }\end{array}$ & $\begin{array}{l}0,178^{* * * *} \\
(0,065)\end{array}$ & $\begin{array}{l}0,282^{* * * *} \\
(0,0582)\end{array}$ & n.s. & $\begin{array}{l}0,161^{*} \\
(0,094)\end{array}$ \\
\hline Constante & $\begin{array}{l}\cdot 2,58^{* * *} \\
(0,552)\end{array}$ & $\begin{array}{l}-3,19 * * * \\
(0,621)\end{array}$ & $\begin{array}{l}-2.25^{* * *} \\
(0,576)\end{array}$ & $\begin{array}{l}-2,00 * * * \\
(0,470)\end{array}$ \\
\hline Pseudo $\cdot R^{2}$ & 0,2249 & 0,3012 & 0,1318 & 0,2005 \\
\hline LR.Chi ${ }^{2}$ & 106,02 & 138,27 & 48,38 & 127,46 \\
\hline $\mathrm{N}$ & 500 & 500 & 500 & 500 \\
\hline
\end{tabular}

1. Regresión logística, participación en asociaciones religiosas es una variable dicotómica; error estándar entre paréntesis. Estimación Probit. Se presentan los efectos marginales evaluados en el promedio de las variables; error estándar entre paréntesis; n.s. indica $>0,1 ; *$ indica $p<0,1 ; * *$ indica $p<0,05$; *** indica $p<0,01$. La técnica de estimación es regresión beta binominal extendida; cada modelo funciona con una variable dependiente: Modelo 1. IPAS índice de participación en asociaciones de voluntariado; Modelo 2. IPAU índice de participación en grupos de interés o utilitarios; Modelo 3. IPAR índice de participación en organizaciones religiosas; Modelo 4. IACD índice de participación en acciones colectivas desafiantes. Bases de datos e informes de índices disponibles en: <http://www.capital-social.com/wp/?page_id=251>.

En el caso de Montevideo, se observa que la participación política tiene efectos en la probabilidad de participación en asociaciones colectivas desafiantes (27,5\%). La actitud de solidaridad y identificación con bienes colectivos tiene efectos en la probabilidad de participar en el voluntariado, los 
grupos de interés y las acciones colectivas $(17,8 \%, 28,2 \%$ y $16,1 \%$ respectivamente). Además, la satisfacción con la democracia se asocia positivamente con la participación en grupos de interés (5\%), y se observa también los efectos de la inseguridad sobre el asociativismo (17\%).

\section{Cuadro 3}

Factores causales de la participación, Porto Alegre

2005

\begin{tabular}{|c|c|c|c|c|}
\hline Variables independientes & Modelo 1: IPAS & $\begin{array}{l}\text { Modelo 2: } \\
\text { IPAU }\end{array}$ & $\begin{array}{l}\text { Modelo 3: } \\
\text { IPAR }^{1}\end{array}$ & $\begin{array}{l}\text { Modelo 4: } \\
\text { IPACD }\end{array}$ \\
\hline Participación voluntariado (IPAS) & $\cdots$ & $\begin{array}{l}0,096 * * \\
(0,0407)\end{array}$ & n.s. & $\begin{array}{l}0,270 * * * \\
(0,074)\end{array}$ \\
\hline Participación grupos de interés (IPAU) & $\begin{array}{l}0,1455^{* * *} \\
(0,0569)\end{array}$ & $\cdots$ & $\begin{array}{l}0,137 \\
(0,094)\end{array}$ & $\begin{array}{l}0,231^{* * * *} \\
(0,077)\end{array}$ \\
\hline $\begin{array}{l}\text { Participación acciones colectivas } \\
\text { (IPACD) }\end{array}$ & $\begin{array}{l}0,1620^{* * * *} \\
(0,049)\end{array}$ & $\begin{array}{l}0,149 * * * \\
(0,044)\end{array}$ & $\begin{array}{l}0,215^{* * * *} \\
(0,0846)\end{array}$ & $\cdots$ \\
\hline Confianza en otra gente (ICG) & n.s. & n.s. & $0,13(0,103)$ & n.s. \\
\hline Confianza instituciones (ICl) & n.s. & n.s. & $\begin{array}{l}0,134^{*} \\
(0,073)\end{array}$ & $.0,106(0,067)$ \\
\hline $\operatorname{Sexo}(S)$ & n.s. & $\begin{array}{l}0,031 \\
(0,019) \\
\end{array}$ & $\begin{array}{l}-0,043 \\
(0,032) \\
\end{array}$ & n.s. \\
\hline Estudios (NE) & n.s. & n.s. & n.s. & n.s. \\
\hline Edad & n.s. & n.s. & n.s. & n.s. \\
\hline Ingresos (NI) & n.s. & n.s. & n.s. & n.s. \\
\hline Infraestructuras asociativas (IEAFI) & n.s. & n.s. & $\cdots$ & $\cdots$ \\
\hline Calidad de vida (ICV) & n.s. & n.s. & n.s. & n.s. \\
\hline Bienestar personal (IBP) & n.s. & n.s. & $\begin{array}{l}-0,079 * \\
(0,045)\end{array}$ & $\begin{array}{l}-0,125^{* * *} \\
(0,039)\end{array}$ \\
\hline Inseguridad (IIN) & $0,011 *(0,072)$ & n.s. & n.s. & n.s. \\
\hline Participar en política & n.s. & n.s. & $\begin{array}{l}-0,134^{* * * *} \\
(0,046)\end{array}$ & $\begin{array}{l}0,144 * * * \\
(0,045)\end{array}$ \\
\hline Satisfacción con la democracia (ISD) & n.s. & n.s. & n.s. & n.s. \\
\hline Solidaridad e identificación (ISOI) & $\begin{array}{l}0,166^{* * *} \\
(0,0409)\end{array}$ & $\begin{array}{l}0,122^{* * * *} \\
(0,034)\end{array}$ & $\begin{array}{l}0,209 * * * \\
(0,0661)\end{array}$ & n.s. \\
\hline Constante & $\begin{array}{l}-3,31 * * * \\
(0,6391) \\
\end{array}$ & $\begin{array}{l}-3,06 * * * \\
(0,688)\end{array}$ & $\begin{array}{l}-1,32 * * * \\
(0,469) \\
\end{array}$ & $\begin{array}{l}-1,50^{* * * *} \\
(0,527) \\
\end{array}$ \\
\hline Pseudo $\cdot \mathrm{R}^{2}$ & 0,2846 & 0,3226 & 0,1331 & 0,2181 \\
\hline LR.Chi ${ }^{2}$ & 88,13 & 87,81 & 58,93 & 85,27 \\
\hline N & 500 & 500 & 500 & 500 \\
\hline
\end{tabular}

1. Regresión logística, participación en asociaciones religiosas es una variable dicotómica; error estándar entre paréntesis. Estimación Probit. Se presentan los efectos marginales evaluados en el promedio de las variables; error estándar entre paréntesis; n.s. indica $>0,1 ; *$ indica $p<0,1 ; * *$ indica $p<0,05$; *** indica $p<0,01$. La técnica de estimación es regresión beta binominal extendida; cada modelo funciona con una variable dependiente: Modelo 1. IPAS índice de participación en asociaciones de voluntariado; Modelo 2. IPAU índice de participación en grupos de interés o utilitarios; Modelo 3. IPAR índice de participación en organizaciones religiosas; Modelo 4. IACD índice de participación en acciones colectivas desafiantes. Bases de datos e informes de índices disponibles en: <http://www.capital-social.com/wp/?page_id=251>. 
OPINIÃO PÚBLICA, Campinas, vol. 18, no 1, Junho, 2012, p. $129-153$

En el caso de Porto Alegre se observa que la participación política tiene efectos en la participación en asociaciones religiosas y acciones colectivas desafiantes, pero en sentido opuesto: la participación política disminuye en un $13,4 \%$ la probabilidad de participar en asociaciones religiosas, y aumenta en un $14,4 \%$ la probabilidad de participar en acciones colectivas. A su turno, la solidaridad e identificación con bienes colectivos tiene efectos en la participación en el voluntariado, en los grupos de interés y en el asociativismo religioso, con impactos de 16,6\%, 12,2\% y 20,8\% respectivamente. La inseguridad tiene también cierto efecto, aunque muy menor ( $1 \%$ en el voluntariado).

\section{Cuadro 4}

Factores causales de la participación, Santiago de Chile 2005

\begin{tabular}{|c|c|c|c|c|}
\hline Variables independientes & Modelo 1: IPAS & Modelo 2: IPAU & Modelo 3: IPAR ${ }^{1}$ & $\begin{array}{l}\text { Modelo 4: } \\
\text { IPACD }\end{array}$ \\
\hline Participación voluntariado (IPAS) & $\cdots$ & $\begin{array}{l}0,1956 * * * \\
(0,0523)\end{array}$ & $\begin{array}{l}0,1919^{*} \\
(0,1168)\end{array}$ & $\begin{array}{l}0,2435^{* * *} \\
(0,086)\end{array}$ \\
\hline $\begin{array}{l}\text { Participación grupos de interés } \\
\text { (IPAU) }\end{array}$ & $0,2341 * * *(0,0557)$ & $\cdots$ & $\begin{array}{l}0,4191^{* * *} \\
(0,1272)\end{array}$ & $\begin{array}{l}0,3956 * * * \\
(0,086)\end{array}$ \\
\hline $\begin{array}{l}\text { Participación acciones colectivas } \\
\text { (IPACD) }\end{array}$ & $0,1969 * * *(0,0446)$ & n.s. & n.s. & $\cdots$ \\
\hline Confianza en otra gente (ICG) & $0,1952 * * *(0,0654)$ & $\begin{array}{l}0,1432 * * * \\
(0,0618)\end{array}$ & n.s. & n.s. \\
\hline Confianza instituciones (ICl) & n.s. & $0,0820(0,0555)$ & $\begin{array}{l}0,4249^{* * *} \\
(0,1152)\end{array}$ & n.s. \\
\hline Sexo (S) & n.s. & $\begin{array}{l}-0,0468 * * \\
(0,0208)\end{array}$ & $.0,071 *(0,041)$ & $0,042(0,027)$ \\
\hline Estudios (NE) & $0,0187 * *(0,0093)$ & n.s. & n.s. & n.s. \\
\hline Edad & $0,0013 * *(0,0006)$ & $\begin{array}{l}0,0015^{* * * *} \\
(0,006)\end{array}$ & n.s. & $\begin{array}{l}-0,006^{* * *} \\
(0,0009)\end{array}$ \\
\hline Ingresos (NI) & n.s. & n.s. & n.s. & n.s. \\
\hline Infraestructuras asociativas (IEAFI) & n.s. & n.s. & $\cdots$ & $\cdots$ \\
\hline Calidad de vida (ICV) & n.s. & n.s. & $.0,1204(0,090)$ & $.0,104 *(0,062)$ \\
\hline Bienestar personal (IBP) & $.0,045(0,0298)$ & n.s. & n.s. & n.s. \\
\hline Inseguridad (IIN) & n.s. & n.s. & $\begin{array}{l}-0,305^{* *} \\
(0,1564)\end{array}$ & n.s. \\
\hline Participar en política & n.s. & n.s. & n.s. & $\begin{array}{l}0,1524^{* * *} \\
(0,039)\end{array}$ \\
\hline Satisfacción con la democracia (ISD) & n.s. & n.s. & n.s. & n.s. \\
\hline Solidaridad e identificación (ISOI) & n.s. & $0,077 *(0,0412)$ & n.s. & n.s. \\
\hline Constante & $\cdot 3,55^{* * *}(0,770)$ & $\cdot 3,55^{* * *}(0,700)$ & n.s. & n.s. \\
\hline Pseudo $\cdot \mathrm{R}^{2}$ & 0,3096 & 0,243 & 0,1057 & 0,2975 \\
\hline LR.Chi ${ }^{2}$ & 103,35 & 75,74 & 60,78 & 133,73 \\
\hline $\mathrm{N}$ & 500 & 500 & 500 & 500 \\
\hline
\end{tabular}

1. Regresión logística, participación en asociaciones religiosas es una variable dicotómica; error estándar entre paréntesis. En el caso de Chile, la pregunta educación contenía categorías de respuesta sobre niveles de educación, mientras que en Montevideo y Porto Alegre contenía años de educación (variable continua), y fue necesario normalizar las respuestas con 0 y 1 (sin educación o con poca educación, con nivel estándar de educación); en el caso de Chile, la pregunta sobre el ingreso tenía categorías de respuesta para que los encuestados se clasificaran según tramos de ingreso, mientras que en los otros casos se preguntaba por cantidades (variable continua), y también fue necesario normalizar (expresar como el logaritmo natural del ingreso reportado mensualmente)

Estimación Probit. Se presentan los efectos marginales evaluados en el promedio de las variables; error estándar entre paréntesis; n.s. indica $>0,1 ;{ }^{*}$ indica $p<0,1$; ** indica $p<0,05$; *** indica $p<0,01$. La técnica de estimación es regresión beta binominal extendida; cada modelo funciona con una variable dependiente: Modelo 1 . IPAS índice de participación en asociaciones de voluntariado; Modelo 2. IPAU índice de participación en grupos de interés o utilitarios; Modelo 3 . IPAR índice de participación en organizaciones religiosas; Modelo 4. IACD índice de participación en acciones colectivas desafiantes. Bases de datos e informes de índices disponibles en: < http://www.capital-social.com/wp/?page_id=251>. 
En el Cuadro 4, caso de Santiago, se observa que la participación y el interés por la política, y la solidaridad e identificación con bienes colectivos tienen efectos en distintas formas de participación. Quienes declaran mayor participación política tienen un 15\% más de probabilidad de participar en acciones colectivas desafiantes, y quienes manifiestan solidaridad e identificación con bienes colectivos tienen un $7 \%$ más de probabilidad de participar en grupos de interés. Por otra parte, cabe observar que la inseguridad o seguridad tiene un efecto muy destacado sobre la disposición a participar.

Con respecto los factores que tienen efectos en la probabilidad de tener confianza social y en las instituciones, los siguientes tres cuadros sintetizan la información del caso.

\section{Cuadro 5}

\section{Factores causales de la confianza, Montevideo \\ 2005}

\begin{tabular}{|c|c|c|}
\hline VD & (ICG) & (ICl) \\
\hline Confianza otra gente (ICG) & $\cdots$ & $0,421 * * *(0,109)$ \\
\hline Confianza instituciones (ICI) & $0,432 * * *(0,115)$ & $\cdots$ \\
\hline Participación Utilitarias & $0,262 * *(0,133)$ & n.s. \\
\hline Participación voluntariado & $-0,141(0,1024)$ & n.s. \\
\hline Participación religiosas & n.s. & $0,147^{* *}(0,065)$ \\
\hline Participación acciones colectivas & $0,205^{* *}(0,089)$ & n.s. \\
\hline Participación política & $0,104 *(0,063)$ & $0,105^{*}(0,060)$ \\
\hline Informarse & $-0,071(0,046)$ & $.0,075^{*}(0,044)$ \\
\hline Satisfacción democracia & $0,091(0,056)$ & $0,131 * * *(0,051)$ \\
\hline Ingresos & n.s. & n.s. \\
\hline Calidad de vida & $0,207 * *(0,082)$ & n.s. \\
\hline Inseguridad & n.s. & n.s. \\
\hline Constante & $.0,543(0,399)$ & $-2,12 * * *(0,516)$ \\
\hline Pseudo - R2 & 0,1443 & 0,1275 \\
\hline LR-Chi2 & 87,16 & 63,43 \\
\hline N & 500 & 500 \\
\hline
\end{tabular}

En Montevideo, la participación en la política influye en la probabilidad de confiar en otra gente $(10,4 \%)$ y en las instituciones (10,5\%). Por otra parte, la gente que no se informa sobre política también tiene mayor probabilidad de confiar $(7,1$ y $7,5 \%$, respectivamente). Finalmente, quienes se sienten satisfechos con la democracia tienen un 13,1\% más probabilidad de confiar en las instituciones. 
OPINIÃO PÚBLICA, Campinas, vol. 18, n 1, Junho, 2012, p. $129-153$

\section{Cuadro 6}

Factores causales de la confianza, Porto Alegre

2005

\begin{tabular}{|c|c|c|}
\hline VD & (ICG) & (ICl) \\
\hline Confianza otra gente (ICG) & $\cdots$ & $0,441^{* * *}(0,128)$ \\
\hline Confianza instituciones (ICl) & $0,5884^{* * *}(0,107)$ & $\cdots$ \\
\hline Participación Utilitarias & n.s. & n.s. \\
\hline Participación voluntariado & $0,194(0,1423)$ & $.0,235^{*}(0,142)$ \\
\hline Participación religiosas & n.s. & $0,095(0,061)$ \\
\hline Participación acciones colectivas & n.s. & $\cdot 0,235^{*}(0,134)$ \\
\hline Participación política & $0,172 * *(0,073)$ & n.s. \\
\hline Informarse & n.s. & n.s. \\
\hline Satisfacción democracia & n.s. & $0,210 * * *(0,057)$ \\
\hline Ingresos & $0,028 * * *(0,0116)$ & n.s. \\
\hline Calidad de vida & n.s. & n.s. \\
\hline Inseguridad & $\cdot 0,502^{* * *}(0,167)$ & n.s. \\
\hline Constante & $\cdot 0,713^{*}(0,388)$ & $-1,603 * * *(0,453)$ \\
\hline Pseudo - R2 & 0,1146 & 0,0665 \\
\hline LR-Chi2 & 78,16 & 39,21 \\
\hline N & 500 & 500 \\
\hline
\end{tabular}

En Porto Alegre, la gente que participa en política y que reporta mayor nivel de seguridad tiene mayor probabilidad de confiar en otra gente $(17,2 \%$ y $50 \%$, respectivamente). Por otra parte, las personas que tienen satisfacción con la democracia tienen un $21 \%$ más de probabilidad de confiar en las instituciones. 
Cuadro 7

Factores causales de la confianza, Santiago

2005

\begin{tabular}{|l|l|l|}
\hline VD & $($ ICG) & $($ ICI) \\
\hline Confianza otra gente (ICG) & $\ldots$ & $0,491^{* * *}(0,1318)$ \\
\hline Confianza instituciones (ICI) & $0,681^{* * *}(0,129)$ & $\cdots$ \\
\hline Participación Utilitarias & n.s. & n.s. \\
\hline Participación voluntariado & $0,283^{*}(0,155)$ & n.s. \\
\hline Participación religiosas & n.s. & $0,107^{* *}(0,050)$ \\
\hline Participación acciones colectivas & $0,222^{*}(0,120)$ & $-0,143(0,106)$ \\
\hline Participación política & $n . s$. & n.s. \\
\hline Informarse & $-0,058^{*}(0,035)$ & $0,043(0,027)$ \\
\hline Satisfacción democracia & n.s. & $0,253^{* * *}(0,057)$ \\
\hline Ingresos & n.s. & $\cdot 0,015(0,010)$ \\
\hline Calidad de vida & $0,124(0,098)$ & n.s. \\
\hline Inseguridad & $0,240(0,180)$ & n.s. \\
\hline Constante & $-1,156^{* * *}(0,351)$ & $-1,83^{* * *}(0,402)$ \\
\hline Pseudo - R2 & 0,0924 & 0,0991 \\
\hline LR-Chi2 & 64,02 & 59,7 \\
\hline N & 500 & 500 \\
\hline
\end{tabular}

n.s. indica $>0,1 ;{ }^{*}$ indica $p<0,1 ;{ }^{* *}$ indica $p<0,05 ; * * *$ indica $p<0,01$. La técnica de estimación es regresión beta binominal extendida; cada modelo funciona con una variable dependiente: Modelo 1. ICG índice de confianza social (en otra gente); Modelo 2. ICI índice de confianza en las instituciones. Bases de datos e informes de índices disponibles en: <http://www.capital. social.com/wp/?page_id=251>.

En Chile, el interés y la participación en la política tienen efectos sobre los dos tipos de confianza social y en las instituciones. La gente que no se informa sobre los asuntos políticos tiene un $5,5 \%$ más de probabilidad de confiar en otra gente, mientras que la gente que declara informarse tiene un $4,3 \%$ más probabilidad de confiar en las instituciones. Por otra parte, la gente que declara satisfacción con la democracia tiene un 25,3\% de mayor probabilidad de confiar en las instituciones. Finalmente, la gente que declara mayor nivel de inseguridad tiene un $24 \%$ de mayor probabilidad de confiar en otra gente.

Sumariamente, la observación de los modelos de regresión en los tres casos arroja un conjunto de variables independientes de naturaleza político-institucional y de cultura política que tienen efectos en la formación del CS, sobre la probabilidad de participar en instancias de vida asociativa y de tener confianza. Primero, en los tres casos, quienes participan en política tienen mayor probabilidad de participan en otras instancias de vida asociativa, en particular en las acciones colectivas desafiantes, en 
menor medida en otras formas de vida asociativa, y tienen disposición a confiar en la otra gente y en las instituciones. Segundo, la satisfacción con la democracia influye en la confianza en las instituciones, y en menor medida en la probabilidad de participar. Tercero, la actitud de solidaridad con bienes colectivos predispone a participar, especialmente en el voluntariado, también en los grupos de interés y en las otras formas de vida asociativa. Cuarto, la seguridad influye también en la participación, en menor medida en la confianza. Después sigue un conjunto bastante heterogéneo de variables causales, cuya importancia en cada caso y en relación con cada forma de asociativismo varía.

Los hallazgos sobre los efectos de la participación política en la vida asociativa, especialmente en las acciones colectivas, son consistentes con otros estudios, donde se subraya que quienes participan y lideran asociaciones tienden a participar en la vida política, más que quienes no lo hacen (para el caso de Chile, Valdivieso 2001; 2008b).

La satisfacción con la democracia expresa el grado de aceptación de los resultados de los gobiernos y de las instituciones, desde la perspectiva de la representación y del desempeño de las políticas, según ha sido subrayado por numerosos estudios (por ejemplo, HAGOPIAN et al, 2005). Por lo tanto, la satisfacción manifiesta el impacto que tienen las decisiones y las políticas públicas en las condiciones de vida de las personas. En los tres casos estudiados, esos efectos influyen en la confianza de las personas en las instituciones, y en menor medida en la disposición a participar en instancias de vida asociativa.

La solidaridad con los bienes colectivos se deriva de la cultura política de las sociedades y su efecto en las competencias de los ciudadanos. En los tres casos, ciertamente dicha disposición predispone a la participación, junto a otros, en torno a metas comunes, y por lo tanto es un gran potencial para el CS, tal como ha sido subrayado por otros estudios (BAQUERO, 2003; VALDIVIESO, 2009).

La seguridad es un tema de alta prioridad pública en los tres países en cuestión, por su fuerte impacto en numerosas dimensiones de la vida social (seguridad económica, seguridad ciudadana, medioambiental, etc.). En buena medida, ella es el resultado también de decisiones políticas y del grado de desempeño que tienen las instituciones y otros agentes públicos.

Concluyendo, las observaciones dejan de manifiesto el impacto de los factores político. institucionales y de la calidad de las instituciones en la formación del CS. En efecto, la existencia de sistemas políticos y electorales inclusivos, integradores, que entren en sintonía con inquietudes ciudadanas, favorecerán la vida asociativa y la confianza, lo mismo que las políticas públicas que sean representativas y tengan buenos resultados en la calidad de vida y la seguridad de las personas, y promuevan la satisfacción con la democracia. Asimismo, las políticas, las prácticas institucionales y todos los factores que promuevan actitudes solidarias, comprometidas con el bien común, contribuyen también a la creación de la vida asociativa, la confianza, y el desarrollo. 


\section{Nivel comunal, caso de Santiago de Chile}

Hasta ahora, en los tres casos de estudio, he encontrado evidencias sobre un moderado stock de vida asociativa y confianza, y el impacto de factores políticos e institucionales en la formación del CS. Para seguir avanzando, en este apartado partiré del supuesto que los factores políticos e institucionales operan en unidades político-administrativas concretas, las comunas, y que las diferencias en las tasas de participación y confianza debiesen ser atribuibles, al menos en parte, a las condiciones políticas y las instituciones locales. Por lo tanto exploraré las diferencias que se observan en las comunas.

El acceso a información sobre las características de las comunas chilenas hace posible hacer el análisis de ese caso. En Santiago, la encuesta de CS fue aplicada en las comunas de La Granja, Pedro Aguirre Cerda, Lo Espejo, Recoleta y Quinta Normal, y en consecuencia asumiré que esas comunas y sus características, especialmente políticas e institucionales, tienen efectos en la probabilidad de participar y tener confianza. El ejercicio metodológico consiste en estimar el efecto que tiene ser o no de una comuna sobre la vida asociativa y la confianza. Para comparar las comunas selecciono una que sirva de punto de referencia, una comuna base. Después incorporo en los análisis cuantitativos cuatro variables dicotómicas que representan a cuatro de las cinco comunas donde se aplico la encuesta. De este modo, por medio de la comparación con la comuna base, es posible rescatar el efecto marginal que genera ser de una comuna.

Observando informaciones sobre las comunas (Cuadro 8) se aprecia que la comuna de Recoleta tiene un conjunto de diferencias con respecto a las demás que justifica su selección como comuna base, es decir, aquella que sirve de punto de referencia para comparar. En Recoleta se observa una densidad de población relativamente moderada (8607), una proporción equilibrada de mujeres y hombres, con bastante población joven. En términos de calidad de vida, la tasa de desempleo está en el promedio nacional $(9,5 \%)$, la mayor parte de la población declara tener medianos ingresos, un alto porcentaje de población dispone de propiedad pagada o pagándose $(59,31 \%)$, y la mayor parte de las personas se siente relativamente más segura (sólo 21,9\% de los encuestados declara tener temor de asaltos en las calles de sus barrios). En Recoleta, el gobierno municipal es proporcional, ya que participan cinco fuerzas políticas distintas (una de las dos coaliciones políticas más importantes del país y otras cuatro fuerzas políticas), dispone de autonomía presupuestaria relativa $(63,82 \%$ de sus ingresos totales son ingresos propios), y exhibe indicadores de un buen desempeño: el 93,32\% de las viviendas cuenta con agua potable, la población tiene una alta tasa de escolaridad relativa (9,72 años), y el $38,2 \%$ de los estudiantes de sus establecimientos municipales obtiene puntajes de PSU para estudiar en la educación superior mayores a 450 puntos. Adicionalmente, la comuna dispone de bastante oferta de vida asociativa (964 organizaciones inscritas en el municipio, con personalidad jurídica). 
OPINIÃO PÚBLICA, Campinas, vol. 18, no 1, Junho, 2012, p. $129-153$

Cuadro 8

\section{Características de las cinco comunas de Santiago} 2003-2006

\begin{tabular}{|c|c|c|c|c|c|}
\hline & Lo Espejo & La Granja & Recoleta & PAC & Quinta Normal \\
\hline Población estimada & 108412 & 130936 & 139439 & 105556 & 97327 \\
\hline Superficie K2 & 7,2 & 10,1 & 16,2 & 9,7 & 12,4 \\
\hline Habitantes por kilómetro cuadrado & 15057,22 & 12936,96 & 8607,35 & 10882,06 & 7848,95 \\
\hline Porcentaje mujeres & 49,23 & 48,74 & 49,04 & 48,46 & 48,84 \\
\hline $\begin{array}{l}\text { Porcentaje jóvenes (menores de } 24 \\
\text { años) }\end{array}$ & 43,07 & 41,08 & 37,75 & 44,76 & 45,59 \\
\hline $\begin{array}{l}\text { Porcentaje maduros (entre } 24 \text { y } 40 \\
\text { años) }\end{array}$ & 21,55 & 21,52 & 21,67 & 22,15 & 22,78 \\
\hline $\begin{array}{l}\text { Porcentaje adultos y mayores } \\
\text { (Mayores de } 50 \text { años) }\end{array}$ & 19,47 & 22,94 & 27,1 & 19,26 & 13,26 \\
\hline Porcentaje bajos ingresos & 27,52 & 5,59 & 22,01 & 27,99 & 12,84 \\
\hline Porcentaje medianos ingresos & 56,06 & 22,86 & 54,84 & 52,19 & 53,78 \\
\hline Porcentaje altos ingresos & 16,41 & 71,55 & 23,15 & 19,82 & 33,39 \\
\hline $\begin{array}{l}\text { Porcentaje de personas con } \\
\text { propiedad pagada o pagándose }\end{array}$ & 76,74 & 67,19 & 59,31 & 69,89 & 81,1 \\
\hline Clubes Deportivos 2005 & 187 & 260 & 274 & 49 & 53 \\
\hline Centros de Madre 2005 & 101 & 75 & 94 & 26 & 30 \\
\hline Centros Adulto Mayor 2005 & 84 & 93 & 83 & 42 & 52 \\
\hline Juntas de Vecinos 2005 & 31 & 78 & 59 & 27 & 29 \\
\hline $\begin{array}{l}\text { Otras Organizaciones Comunitarias } \\
\text { Funcionales } 2005\end{array}$ & 99 & 371 & 408 & 49 & 150 \\
\hline $\begin{array}{l}\text { Organizaciones Comunitarias con } \\
\text { Personalidad Jurídica } 2005\end{array}$ & 543 & 931 & 964 & 206 & 336 \\
\hline $\begin{array}{l}\text { Fecha del último PLADECO (Plan } \\
\text { de Desarrollo Comunal) }\end{array}$ & 2006 & 2004 & 2010 & 2009 & 2009 \\
\hline $\begin{array}{l}\text { Ingresos Propios/ Total Ingreso } \\
2005\end{array}$ & 18,22 & 19,05 & 63,82 & 25,32 & 52,31 \\
\hline Ingresos FCM/Total Ingreso 2005 & 69,53 & 68,03 & 15,93 & 56,1 & 19,62 \\
\hline Número de Concejales Alianza & 1 & 1 & 0 & 2 & 0 \\
\hline $\begin{array}{l}\text { Número de Concejales } \\
\text { Concertación }\end{array}$ & 1 & 1 & 4 & 2 & 2 \\
\hline $\begin{array}{l}\text { Número de Concejales Otra } \\
\text { Coalición }\end{array}$ & 4 & 4 & 4 & 4 & 4 \\
\hline $\begin{array}{l}\text { Percepción de vulnerabilidad al } \\
\text { delito (Qué tan seguro se siente } \\
\text { caminando solo por su barrio } \\
\text { cuando ya está oscuro? Opción } \\
\text { inseguro y muy inseguro) }\end{array}$ & 31,2 & 29,4 & 21,9 & 22,1 & 27,3 \\
\hline $\begin{array}{l}\text { Percepción de evolución del delito } \\
\text { (Pensando en la delincuencia, } \\
\text { ¿Usted diría que en los últimos } \\
\text { doce meses la delincuencia } \\
\text { aumentó?) }\end{array}$ & 63,9 & 63 & 68,5 & 53,1 & 39,3 \\
\hline $\begin{array}{l}\text { Tasas de desempleo por comuna } \\
2003\end{array}$ & $11,23 \%$ & $5,57 \%$ & $9,51 \%$ & $12,04 \%$ & $10,77 \%$ \\
\hline Cobertura de Agua Potable (\%) & 97,27 & 96,68 & 93,32 & 96,13 & 93,79 \\
\hline $\begin{array}{l}\text { Porcentaje de Puntajes PSU (a } \\
\text { partir del 2003) Igual o Superior a } \\
450 \text { Puntos en Establecimientos } \\
\text { Municipales de Educación (\%) }\end{array}$ & 20 & 14,71 & 38,18 & 18,67 & 37,97 \\
\hline $\begin{array}{l}\text { Escolaridad Promedio de la } \\
\text { Población }\end{array}$ & 8,88 & 9,35 & 9,72 & 9,57 & 9,98 \\
\hline
\end{tabular}


Al incluir en el análisis de los datos cuatro de las cinco comunas como variables independientes, con el propósito de evaluar el impacto que tienen en la decisión de participar en la vida asociativa y la confianza, se obtiene el Cuadro 9.

\section{Cuadro 9}

Factores de la participación, Chile

2005

\begin{tabular}{|c|c|c|c|c|}
\hline Variables independientes & Modelo 1: IPAS & Modelo 2: IPAU & Modelo 3: IPAR ${ }^{1}$ & $\begin{array}{l}\text { Modelo 4: } \\
\text { IPACD }\end{array}$ \\
\hline Participación voluntariado (IPAS) & $\cdots$ & $\begin{array}{l}0,1464 * * * \\
(0,0470)\end{array}$ & $0,355^{* * *}(0,1257)$ & $0,205^{* * *}(0,077)$ \\
\hline Participación grupos de interés (IPAU) & $\begin{array}{l}0,2160 * * * \\
(0,0546)\end{array}$ & $\cdots$ & $\begin{array}{l}0,1595^{* * *} \\
(0,1133)\end{array}$ & $0,343^{* * *}(0,081)$ \\
\hline Participación acciones colectivas (IPACD) & $\begin{array}{l}0,1706 * * * \\
(0,0431)\end{array}$ & n.s. & n.s. & $\cdots$ \\
\hline Confianza en otra gente (ICG) & $0,162 * * *(0,0623)$ & $0,1382 * * *(0,055)$ & n.s. & n.s. \\
\hline Confianza grandes organizaciones (ICGO) & $\ldots$ & $\ldots$ & $\ldots$ & $\ldots$ \\
\hline Confianza instituciones (ICI) & n.s. & n.s. & $\begin{array}{l}0,3813^{* * * *} \\
(0,1166)\end{array}$ & $-0,124 *(0,071)$ \\
\hline Confianza elites (ICE) & $\cdots$ & $\cdots$ & $\cdots$ & $\cdots$ \\
\hline Confianza org. informales (ICOI) & $\cdots$ & a & $\cdots$ & $\cdots$ \\
\hline $\operatorname{Sexo}(S)$ & n.s. & $\begin{array}{l}0,0397 * * \\
(0,01786)\end{array}$ & $-0,069 *(0,040)$ & $0,0379(0,0249)$ \\
\hline Estudios (NE) & $0,0175 *(0,0087)$ & n.s. & n.s. & n.s. \\
\hline Edad & $0,0012^{* *}(0,0006)$ & $\begin{array}{l}0,0013^{* * * *} \\
(0,0053)\end{array}$ & n.s. & $\begin{array}{l}-0,0005^{* * *} \\
(0,0009)\end{array}$ \\
\hline Ingresos (NI) & n.s. & n.s. & n.s. & n.s. \\
\hline Infraestructuras asociativas (IEAFI) & $\cdots$ & $\cdots$ & $\cdots$ & $\ldots$ \\
\hline Calidad de vida (ICV) & n.s. & n.s. & $\cdot 0,138(0,0916)$ & $\begin{array}{l}-0,0907 \\
(0,0577)\end{array}$ \\
\hline Bienestar personal (IBP) & n.s. & n.s. & n.s. & n.s. \\
\hline Inseguridad (IIN) & n.s. & n.s. & n.s. & n.s. \\
\hline Participar en política & $0,0402(0,0279)$ & n.s. & n.s. & $\begin{array}{l}0,1355^{* * *} \\
(0,0359)\end{array}$ \\
\hline Satisfacción con la democracia (ISD) & n.s. & n.s. & n.s. & n.s. \\
\hline Apoyo a la Democracia (IAD) & $\cdots$ & 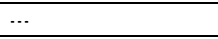 & $\cdots$ & $\cdots$ \\
\hline Solidaridad e identificación (ISOI) & n.s. & $0,076 * *(0,0352)$ & n.s. & n.s. \\
\hline La Granja & n.s. & $\begin{array}{l}-0,0453^{* * *} \\
(0,0152)\end{array}$ & n.s. & n.s. \\
\hline Lo Espejo & $0,056(0,047)$ & $.0,0275 *(0,0167)$ & $0,224 * * *(0,076)$ & n.s. \\
\hline Pedro Aguirre Cerda & $0,0705(0,0489)$ & n.s. & $0,171 * *(0,0717)$ & n.s. \\
\hline Quinta Normal & n.s. & $\begin{array}{l}-0,0587^{* * *} \\
(0,0157)\end{array}$ & $-0,177^{* * *}(0,0501)$ & $\begin{array}{l}-0,095^{* * *} \\
(0,024)\end{array}$ \\
\hline Constante & $\begin{array}{l}-4,1773^{* * *} \\
(0,8030)\end{array}$ & $-2,622^{* * *}(0,700)$ & $\cdot 1,11^{* *}(0,5284)$ & n.s. \\
\hline Pseudo $\cdot \mathrm{R}^{2}$ & 0,3311 & 0,2882 & 0,176 & 0,3358 \\
\hline LR-Chi ${ }^{2}$ & 110,5 & 89,82 & 101,22 & 150,95 \\
\hline $\mathrm{N}$ & 500 & 500 & 500 & 500 \\
\hline
\end{tabular}

Estimación Probit. Se presentan los efectos marginales evaluados en el promedio de las variables; error estándar entre paréntesis; n.s. indica $>0,1$; ${ }^{*}$ indica $p<0,1$; $^{*}$ indica $p<0,05$; ** indica $p<0,01$. La técnica de estimación es regresión beta binominal extendida; cada modelo funciona con una variable dependiente: Modelo 1. IPAS índice de participación en asociaciones de voluntariado; Modelo 2. IPAU índice de participación en grupos de interés o utilitarios; Modelo 3 . IPAR índice de participación en organizaciones religiosas; Modelo 4. IACD índice de participación en acciones colectivas desafiantes. Bases de datos e informes de índices disponibles en: <http://www.capital-social.com/wp/?page_id=25>.

En el Cuadro se observa que las variables de naturaleza política mantienen su impacto en la probabilidad de participar y de sentir confianza: la participación política genera un $4 \%$ más de probabilidad de participar en voluntariado, y $13,5 \%$ de participar en asociaciones colectivas; la actitud 
de solidaridad e identificación tiene el efecto de un 7,6\% en la probabilidad de participar en asociaciones religiosas. Las comunas influyen diferenciadamente en la probabilidad de participar: residir en la comuna de la Granja implica tener 4,5\% menos de probabilidad de participar en la vida asociativa de grupos de interés que residir en Recoleta; lo mismo ocurre en los casos de las comunas de Lo Espejo y Quinta Normal, donde hay un $2,7 \%$ y un $5,8 \%$ menos de probabilidad de participar que en Recoleta. Pero residir en Lo Espejo y en Pedro Aguirre Cerda aumenta la probabilidad de participar en asociaciones religiosas, con respecto a Recoleta, en 22,4 y 17,1\% respectivamente, mientras que en Quita Normal hay un 17,7\% menos de probabilidad. Finalmente, en Quinta Normal existe un 9,5\% menos de probabilidad de participar en acciones colectivas desafiantes que en Recoleta.

En cuanto a la confianza (Cuadro 10) se observa que las personas de La Granja, Lo Espejo y Quinta Normal tienen mayor probabilidad de tener confianza social que las de Recoleta $(16 \%, 29 \%$ y $27 \%$ respectivamente). Pero la gente de las mismas comunas no tiene la misma probabilidad de tener mayor confianza en las instituciones, y en el caso de Lo Espejo hay probabilidad de tener menor confianza (-10\%). Sumariamente, quienes son de las comunas de Lo Espejo, La Granja y Quinta Normal tienen menor probabilidad de participar en instancias de vida asociativa (voluntariado y acciones colectivas) que quienes viven en Recoleta, y en las mismas comunas tiende a existir más confianza social, pero no así en las instituciones. Estas últimas constataciones están en plena sintonía con las observaciones de otros estudios, en distintos contextos, donde se observa que la confianza social no se traduce, necesariamente, en confianza política y mayor participación (KIM, 2005).

Cuadro 10

Factores de la confianza, Chile

2005

\begin{tabular}{|c|c|c|}
\hline VD & (ICG) & (ICI) \\
\hline Confianza otra gente (ICG) & $\ldots$ & $0,528^{* * *}(0,1346)$ \\
\hline Confianza instituciones (ICI) & $0,789 * * *(0,135)$ & $\cdots$ \\
\hline Participación Utilitarias & n.s. & n.s. \\
\hline Participación voluntariado & $0,252(0,156)$ & n.s. \\
\hline Participación religiosas & n.s. & $0,118^{* *}(0,053)$ \\
\hline Participación acciones colectivas & $0,230 *(0,125)$ & $.0,140(0,108)$ \\
\hline Participación política & n.s. & n.s. \\
\hline Informarse & $-0,062 *(0,037)$ & $0,038(0,027)$ \\
\hline Satisfacción democracia & n.s. & $0,252^{* * * *}(0,057)$ \\
\hline Sentido comunitario & $\ldots$ & $\ldots$ \\
\hline Ingresos & n.s. & n.s. \\
\hline Infraestructuras & $\cdots$ & 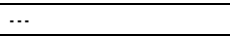 \\
\hline Calidad de vida & $0,208 * *(0,1028)$ & n.s. \\
\hline Inseguridad & $0,263(0,193)$ & n.s. \\
\hline La Granja & $0,162^{* * *}(0,0728)$ & n.s. \\
\hline Lo Espejo & $0,289 * * *(0,067)$ & $.0,097(0,060)$ \\
\hline Pedro Aguirre Cerda & n.s. & n.s. \\
\hline Quinta Normal & $0,273 * * *(0,069)$ & n.s. \\
\hline Constante & $-1,805^{* * *}(0,4055)$ & $-1,670 * * *(0,432)$ \\
\hline Pseudo - R2 & 0,1258 & 0,1079 \\
\hline LR-Chi2 & 87,17 & 64,96 \\
\hline $\mathrm{N}$ & 500 & 500 \\
\hline
\end{tabular}

n.s. indica $>0,1 ; *$ indica $p<0,1 ; * *$ indica $p<0,05 ; * * *$ indica $p<0,01$. La técnica de estimación es regresión beta binominal extendida; cada modelo funciona con una variable dependiente: Modelo 1. ICG índice de confianza social (en otra gente); Modelo 2. ICI índice de confianza en las instituciones. Bases de datos e informes de índices disponibles en: <http://www.capital. social.com/wp/?page_id=251>. 
VALDIVIESO, P. Capital social y participación, una perspectiva desde el Cono Sur...

Con los datos del Cuadro 8 es posible identificar factores que ayuden a explicar las diferencias constatadas. En el Cuadro se observa que los municipios de las comunas de Lo Espejo, La Granja y Quinta Normal disponen de menos recursos propios que Recoleta, y por lo tanto tienen menor autonomía presupuestaria. Además, en esas comunas hay mayor percepción de inseguridad ciudadana (delitos), y en ellas las personas tienen menores tasas de escolaridad, lo que sugiere un más bajo desempeño de los municipios y los establecimientos educacionales relacionados. Esos tres factores, relativamente deficitarios en las tres comunas en comento, son el resultado de las políticas públicas y del funcionamiento de las instituciones.

En la literatura del CS se ha destacado el efecto que tienen las estructuras federales, la descentralización y la autonomía local en la formación del CS (FREITAG, 2006). Ellas generarían mayores incentivos que las estructuras centralizadas para la vida asociativa, por dar la posibilidad de una intervención más directa de las comunidades territoriales en los procesos de toma de decisión. A partir de ese supuesto, en el caso de Chile es razonable esperar que la mayor autonomía presupuestaria influya en la estructura de los incentivos de las comunidades territoriales. En efecto, la mayor autonomía presupuestaria amplía los márgenes de maniobra de los gobiernos municipales para acoger iniciativas de los vecinos, para gestionar y poner en práctica políticas, programas e instrumentos que promuevan la participación.

En América Latina, la seguridad ha pasado a ser un tema de alta connotación pública, y la mayor parte de los estudios de opinión sugieren que los ciudadanos ponen cada vez mayor atención en los logros y fracasos de los gobiernos y de las instituciones públicas, cuanto tienen que evaluar y tomar decisiones. Las personas perciben que las autoridades políticas y las instituciones son los principales responsables en la provisión de ese bien público, y valoran positiva o negativamente su desempeño según ese criterio. Por lo tanto es razonable considerar la percepción que tienen los ciudadanos sobre la seguridad como una suerte de indicador de los resultados que tienen las políticas y programas de los gobiernos en sus condiciones de vida, un indicador que naturalmente genera incentivos para la vida asociativa y la confianza en las comunas.

En Chile, el sistema educacional delega una alta cuota de responsabilidad a los municipios, entidades que intervienen en la distribución del presupuesto para educación, y en el control directo o indirecto de los establecimientos educacionales. Por esta razón, la escolaridad en las comunas es un indicador del desempeño de las políticas y las instituciones de los gobiernos nacionales y locales. En tal sentido, la tasa de escolaridad es un indicador del desempeño de las propias autoridades municipales y sus programas, y es razonable esperar que tenga efectos sobre la vida asociativa y la confianza en las comunas. Por otra parte es razonable esperar también que la escolaridad, en cuanto indicador de formación de las personas, influya en sus destrezas y competencias para informarse, discernir con responsabilidad y decidir en consecuencia, es decir, en su cultura política.

\section{Recapitulación y hallazgos}

Sumariamente, el CS, observado por medio de la participación en la vida asociativa y la confianza muestra algunas tendencias similares y diferencias en los tres casos sudamericanos. 
Primero, el nivel de vida asociativa es modesto, comparable con lo que se ha observado en otros lugares del mundo. Lo anterior no significa, necesariamente, que haya una erosión del CS y de la participación, ya que los formatos de la vida asociativa pueden estar cambiando. De hecho, si uno compara entre las categorías incluidas en este estudio (voluntariado, grupos de interés, grupos religiosos y acciones colectivas), se observa que mientras la participación en el voluntariado tiende a ser baja en los tres casos, la participación en acciones colectivas es relativamente más alta. Ello obedece a que los contextos y los referentes de la participación cambian en el tiempo y en el espacio, y vehículos de la vida asociativa estructurada que pueden haber incentivado la decisión de las personas por participar en algún periodo histórico dejan de hacerlo en otros. Por ejemplo, los sindicatos o los partidos políticos pierden vitalidad en la actualidad, porque las personas tienden a identificarse con otros referentes, interactúan en múltiples relaciones sociales sólo parcialmente, y tienden a tomar la decisión de participar cuando disponen de ofertas de vida asociativa menos estructuradas, que sintonicen mejor con cuestiones muy concretas que afectan sus intereses y sus vidas. Tal vez por esta razón las huelgas o los movimientos de protesta generan mayores incentivos para participar, como se observa en la encuesta del 2005.

Segundo, la alta participación política convencional que se observa, en términos de ir a votar a las urnas, demuestra que en las decisiones de participar influyen también aspectos institucionales o estructurales, que condicionan los comportamientos. En los tres casos investigados, la legislación sobre votaciones tiene efectos en las altas tasas de participación electoral.

Tercero, cabe hacer notar que el asociativismo tiende a ser mayor en el caso de Montevideo, excepto en relación con las asociaciones de carácter religioso, lo cual es consistente con el mayor grado de secularización de Uruguay, en comparación con Brasil y Chile. Desde la perspectiva comparada del asociativismo, al ser Montevideo el caso donde se observa mayor disposición de la población a la participación, el conocimiento más detallado de esa experiencia podría ser muy provechoso en términos de aprendizaje sobre incentivos que influyen en la formación del CS. Probablemente, una observación más detallada del contexto socio-político y económico de Uruguay el año 2005, cuando se aplicó la encuesta en Montevideo, ayudará a entender mejor esas tendencias. En efecto, Uruguay ha destacado en el concierto latinoamericano por su trayectoria democrática, el alto nivel educacional y de cultura cívica de su población, y el 2005 experimentaba un complejo proceso de transición política hacia un gobierno de izquierda con un renovado ciclo de participación social e interés por la política.

Cuarto, en los tres casos hay modestos niveles de confianza en las instituciones. Lo anterior es consistente con percepciones sobre una crisis de la legitimidad de los sistemas políticos y sus instituciones, en contextos donde la brecha entre inquietudes ciudadanas y el resultado del quehacer de las instituciones aumenta y genera preocupación (VALDIVIESO 2003, 2008). Por otra parte, la erosión de la confianza va de la mano con la creciente debilidad y falta de legitimidad de otrora importantes instituciones y formas de relación social, tales como son los parlamentos, los poderes judiciales, los partidos políticos y las asociaciones sindicales. El mayor grado de confianza social sugiere un alto potencial de CS, que favorece la cohesión social, la cooperación, la estabilidad política y el desarrollo, no obstante numerosas condiciones económicas y sociales adversas en la última década. Esta tendencia es consistente con los efectos de una cultura política, en la cual la solidaridad e identificación con los bienes colectivos tiene efectos en las decisiones de las personas. 
VALDIVIESO, P. Capital social y participación, una perspectiva desde el Cono Sur...

Algunas de las relaciones observadas sugieren áreas de particular interés para una mayor comprensión de los procesos de formación del CS y para fortalecer condiciones sociales del desarrollo y de la estabilidad democrática.

Primero, hay una relación positiva entre el asociativismo y la participación política, la mayor experiencia asociativa incide en la participación política, y por lo tanto la extensión de ese tipo de actividad podría beneficiar la estabilidad del sistema democrático. Lo mismo se puede indicar en relación con la solidaridad e identificación con bienes colectivos, cuya mayor extensión podría incidir en la cohesión social y en la estabilidad democrática.

Segundo, a diferencia de numerosos trabajos, las relaciones observadas y sintetizadas en este estudio previenen sobre la dificultad de llegar a conclusiones a partir de la consideración de ciertas formas particulares de vida asociativa, pasando por alto que ellas no se dan de forma pura ni aislada. Las observaciones de los datos, validadas por medio de diversas consultas en Montevideo, Porto Alegre y Santiago de Chile (especialistas y comunidades varias) conducen a pensar que la experiencia acumulada en la práctica de la vida asociativa puede ser una condición favorable para la formación de CS; así se observa, por ejemplo, que la probabilidad de participar en asociaciones de voluntariado se incremente con la experiencia de participación en otros tipos de asociaciones. En este sentido, cabe subrayar que es difícil afirmar que el mayor grado de CS sea resultado de la participación en ciertos tipos específicos de asociación y no en otras actividades, como lo suponía Putnam al reflexionar sobre las causas de la erosión de la vida asociativa en los Estados Unidos (PUTNAM, 2000). Por el contrario, las evidencias de los casos sudamericanos apuntan hacia relaciones interdependientes, positivas con respecto a la vida asociativa, por ejemplo la experiencia de participación en grupos de interés promovería una competencia importante para la partición en acciones colectivas, y viceversa.

Tercero, las relaciones observadas entre vida asociativa y confianza coinciden con las evidencias y afirmaciones de numerosos estudios sobre la estrecha relación entre ambas, no obstante los matices que puedan advertirse, según el contexto espacial, temporal y socio-económico del que se trate.

Cuarto, los casos sudamericanos suman evidencias en torno a la estrecha relación que existe entre la política, las instituciones y la cultura política, por una parte, y los comportamientos sociales, en este caso vida asociativa y confianza. En la misma dirección de otros estudios que dan especial importancia a los efectos de las instituciones y de los gobiernos en la formación del CS (FREITAG, 2006; KEELE, 2007), aquí se observan claras relaciones entre los efectos del desempeño de las instituciones, la confianza en las instituciones, la participación política y las probabilidades de participar en la vida asociativa y tener confianza. En otras palabras, el desempeño de los gobiernos y de las instituciones, la confianza pública y la participación influyen en las decisiones individuales que conducen a la formación del CS. Por lo tanto, la mayor sintonía entre el desempeño (resultados) del sistema político y de las instituciones, por una parte, y las inquietudes ciudadanas, por otra, debiera conducir a una mayor acumulación de CS.

Metodológicamente, este estudio deja algunos aprendizajes de interés para la investigación el CS:

Primero, hay que seguir avanzando por el camino de la investigación de casos concretos, caso a caso, porque ello se traducirá en mayor conocimiento y mejores condiciones para la comparación, y 
por lo tanto para la formulación de modelos y la fundamentación de intervenciones y políticas. Los estudios de casos resultan ser un método adecuado para poder observar dónde están operando variables que son de importancia, dónde se están generando dinámicas de interés, que quedan escondidas detrás de visiones en el nivel macro. Ciertamente, las evidencias arrojadas por los estudios de casos deben complementar visiones que postulen hipótesis de relación a partir de la información agregada.

Segundo, se debe tener en cuenta que las tendencias ya observadas, al igual que las correlaciones y las causalidades, se dan en contextos distintos, y por lo tanto los análisis y las generalizaciones que se puedan extraer son sólo aproximaciones que podrán ir siendo afinadas con nuevas observaciones que sean comparables. En este sentido, las observaciones pueden ser consideradas pautas en relación a situaciones y problemas similares, bajo condiciones espacio. temporales y sociales distintas en Porto Alegre, Santiago de Chile y Montevideo. Esta constatación es válida para todos los estudios comparados del Capital Social.

Tercero, algunas relaciones entre índices del CS, variables socio-económicas y demográficas y de cultura política son significativas y altas, mayores que aquellas observadas en la literatura mundial revisada sobre el particular. Esto último podría obedecer al muestreo, a los instrumentos de medición o a cambios en las propias variables que son consideradas en el transcurso del tiempo (entre una medición y otra). No es posible sacar conclusiones definitivas, faltan series temporales para poder hacer mayores comparaciones y precisar impresiones, y afirmar lo contrario sería artificial.

\section{Referencias Bibliográficas}

BAQUERO, M. Alcances e limites do capital social na construção democrática. BAQUERO, M. (Ed.). Reinventando a Sociedade na América Latina: Cultura Política, Gênero, Exclusão e Capital Social. Porto Alegre: Ed. da UFRGS, 2003.

Democracia e Desigualdades na América Latina. Porto Alegre: Ed. da UFRGS, 2007.

BOURDIEU, P. "Le capital social. Notes provisores". Actes de la Recherche en Sciences Sociale, n. 31, p. 2.3, 1980.

BUQUET, D. (org.). Las claves del cambio: Ciclo electoral y nuevo gobierno 2004/2005. Montevideo: Ediciones de la Banda Oriental, S.R.L., 2005.

CASTILLO, A M. J. La compleja relación entre capital social y confianza política desde el sur de Europa. Evidencia empírica de Andalucía. En: TORCAL, M. et al (orgs.). Desde la esquina de Europa. Análisis comparado del capital social en Andalucía, España y Europa. Consejería de la Presidencia. Junta de Andalucía, Centro de Estudios Andaluces, p. 57.88, 2005.

COLEMAN, J.S. Foundations of social theory. Cambridge: Harvard University Press, 1990.

DETJEN, J. "Die Demokratiekompetenz der Bürger. Herausforderung für die politische Bildung". Aus Politki und Zeitgeschichte, n. 25, p. 7-12, 2000.

FREITAG, M. "Bowling the State back in: Political Institutions and the Creation of Social Capital". European Journal of Political Research, v. 45, n. 1, p. 123-152, 2006.

GEISSEL, B. "Kritische Bürgerinnen und Bürger - Gefahr für Demokratien?". Aus Politik und Zeitgeschichte, 12, 3.9, März 2006.

HAGOPIAN, F.; MAINWARING, S. P. The Third Wave of Democratization in Latin America: Advances and Setbacks. Cambridge: Cambridge University Press, 2005.

KEELE, L. "Social Capital and the Dynamics of Trust in Government". American Journal of Political Science, v. 2, p.241.254, 2007. 
KIM, JI-YOUNG. "'Bowling Together' isn't a Cure-All: The Relationship between Social Capital and Political Trust in South Korea". International Political Science Review, v. 26, n. 2, p. 193.213, 2005.

LOCKE, J. Second Treatise of Government.In: CAHN. M. (ed.). Classics of Political and Moral Philosophy. N. York: Oxford University Press, p. 461.505, 2002.

CAMPOS, T. M. A. Identidade da renovação carismática católica em Brasília e em Santiago do Chile. Tese de Doutorado: Universidade de Brasília, Brasília, 2004.

NORRIS, P. Democratic Phoenix: Reinventing Political Activism. Cambridge: Cambridge University Press, 2002.

OSTROM, E. Governing the Commons: The Evolution of Institutions for Collective Action. Cambridge: Cambridge University Press, 1990.

PUTNAM, R.D. Making Democracy Work: Civic Traditions in Modern Italy. Princeton: Princeton University Press, 1993.

“Bowling alone: America’s Declining Social Capital”. Journal of Democracy, 6, p. 65-78, 1995.

ROSE, R. "Getting things done in an anti-modern society: Social Capital networks in Russia. Social Capital Iniciative". The World Bank. Working Paper, n.6, 1996.

RUBENSON, D. Can Social Capital Account for Differences in Political Participation Across American Cities? In: 2005 APSA Annual Meeting, Washington D.C.

STEIN, E. et al. (cords.). The Politics of Policies: Economic and Social Progress in Latin America. 2006. Report. Interamerican Development Bank, David Rockfeller Center for Latin American Studies, Harvard University, 2006.

TILLY, C.; TILLY, L.; TILLY, R. The Rebellious Century 1830-1930. Cambridge: Harvard University Press, 1975.

VALDIVIESO, P. "Liderazgos, democracia y Formación Política Ciudadana". Estudios Sociales, CPU, n. 107, p. 34-60, 2001.

"Capital social, crisis de la democracia y educación ciudadana: la experiencia chilena". Revista de Sociologia e Política, 21, p. 13.34, 2003.

“Estrategias de Acercamiento a las nuevas Elites". Dialogo Político, 3, p. 150-180, 2008a.

“Propuesta para le progreso de la administración pública y de la gestión local con participación ciudadana, desde la perspectiva del caso de Chile“. Documentos y Aportes en Administración Pública y Gestión Estatal (Santa Fe), A.8, 11, p.89.123, 2008b.

"Capital social e desenvolvimento democrático: Porto Alegre (Brasil) e Santiago do Chile". Revista Brasileira de Ciências Sociais, v.24, n.69, p.34.68, 2009.

YAFFÉ, J. Al centro y adentro. La renovación de la izquierda y el triunfo del Frente Amplio en Uruguay. Montevideo: Librería Linardi y Risso, 2005.

WELZEN, C.; INGLEHART, R. y DEUTSCH, F. Social Capital, Voluntary Associations and Collective Action: Which Aspects of Social Capital Have the Greatest "Civic" Payoff?. In: 2005 APSA Annual Meeting, Washington D.C.

Patricio Valdivieso - pvaldvf@uc.cl

Recebido para publicação em janeiro de 2011. Aprovado para publicação em novembro de 2011 